\title{
Hyaline fibromatosis syndrome: cutaneous manifestations ${ }^{*}$
}

\author{
Silvio Alencar Marques ${ }^{1}$ \\ Juliana Ocanha Polizel ${ }^{1}$ \\ Marcela Calixto Brandão ${ }^{1}$
}

\author{
Hamilton Ometto Stolf ${ }^{1}$ \\ Tânia Munhoz ${ }^{1}$ \\ Mariangela Esther Alencar Marques ${ }^{1}$
}

DOI: http://dx.doi.org/10.1590/abd1806-4841.20163799

\begin{abstract}
Hyaline fibromatosis syndrome is the current name for clinical manifestations of diseases previously known as "infantile systemic hyalinosis" and "juvenile hyaline fibromatosis". The authors report representative clinical cases of each one of the above subtypes with emphasis on cutaneous manifestations and difficulties for early diagnosis in this syndrome, essentially of multidisciplinary approach.
\end{abstract}

Keywords: Fibroma; Gingival hypertrophy; Skin: Skin manifestations; Mutation

\section{INTRODUCTION}

Infantile systemic hyalinosis (ISH) and juvenile hyaline fibromatosis (JHF) are very rare recessive autosomal hereditary diseases that arise from mutation of gene ANTXR2 (anthrax toxin receptor-2), also known as gene CMG2 (capillary morphogenesis gene$2)$, located in chromosome $4 q 21 .^{1,2}$ Such entities have been grouped since 2009 as expressions of distinct severity of the same disease, now designated as hyaline fibromatosis syndrome (HFS). ${ }^{3,4}$ As part of this concept, patients would have expressions of less intense symptoms (JHF) or severe and even lethal forms (ISH), with different genotypic and phenotypic intermediary possibilities. A common marker of the syndrome is the onset, in the first or earlier years in life, of papular-nodular cutaneous lesions, gingival hypertrophy and osteoarticular symptoms with limitation of movements. ${ }^{5-8}$ Such manifestations have an evolutionary course of different magnitudes and severities to which may be added systemic involvement with clinical re- percussion that will impact quality and life span of carriers. The common substract for tissue lesions is the production and anomalous accumulation of hyaline material, not clearly identified, in which certain classes of metalloproteinases and proteoglycans predominate., ${ }^{9,10}$ When such material accumulates in the papillary and reticular dermis and mucosae it gives rise to papular and nodular type lesions and even tumors, and accumulation in tissues of different organs will compromise their specific functions. Osteoarticular involvement particularly affects greater joints causing movement limitation and frequently confining patients to bed or wheelchair. Even though HFS requires multidisciplinary care, it has particular importance for the dermatologist, regarding both early diagnosis and surgical intervention, initiatives aiming to minimize impact of the disease. The authors' objective is to highlight cutaneous manifestations, which are representative of this syndrome.

Approved by the Advisory Board and accepted for publication on 13.10.2014

Work performed at Departamento de Dermatologia e Radioterapia. Faculdade de Medicina de Botucatu - Universidade Estadual Paulista "Júlio de Mesquita Filho" (Unesp) - Botucatu (SP), Brazil.

Financial Support: None.

Conflict of Interest: None.

1 Universidade Estadual Paulista "Júlio de Mesquita Filho" (Unesp) - Botucatu (SP), Brazil.

(C)2016 by Anais Brasileiros de Dermatologia 


\section{CASE REPORTS}

\section{Case 1}

This male patient had his first appointment at a Dermatology outpatient care at two years of age with a history of lesions on the face that had been present for one year. According to the accompanying person, since birth dermatological symptoms were associated with diarrhea as well as neuromotor development retardation and painful upper and lower limbs movement. At the dermatological examination pearl-like papules were observed in the glabellar and eyelid margin regions, as well as isolated and confluent erythematous papules located on the chin, on the nasolabial folds, bilateral retroauricular and auricular regions. On anterior and posterior cervical region lesions converged forming infiltrated plaques that occurred also on the intergluteal cleft and perianal regions. Oral cavity examination showed intense gingival hyperplasia, which partially buried the patient's teeth. His parents were first-degree relatives and did not present any clinical or dermatological alteration. At this opportunity the hypotheses from the Dermatology staff were "lipoid proteinosis" and "Cowden syndrome". Patient underwent cutaneous biopsy and was referred to medical genetics and to pediatric specialties for follow-up. The diagnosis of infantile systemic hyalinosis was suggested by the Pediatric Rheumatology staff and the patient was from this point on managed by Pediatric Gastroenterology due to clinical picture of profuse chronic diarrhea.

The Dermatology team had the opportunity to review the patient on several occasions and the lesions progressively reached larger diameters provoking deformities in the auricular pavilion, nasal pyramid and large joints of lower limbs associated with gingival hyperplasia (Figures 1, 2 and 3). Cutaneous and gastrointestinal tract biopsies corroborated the clinical diagnosis of ISH (Figure 4).

\section{Case 2}

This female patient had an appointment at the Dermatology outpatient care at the age of 4 years complaining about pearl-like papular lesions located on the posterior cervical region. Parents were not consanguineous. She had been examined without definite diagnosis at a Pediatric Rheumatology clinic due to symptoms of upper and lower limbs and movement limitation present since her first year of life. Clinical and histopathological diagnosis by Dermatology team at that time was "juvenile colloid milium". Diagnosis of juvenile hyaline fibromatosis was established by the Pediatric Rheumatology staff when the patient completed seven years of age due to combination of restrictive osteoarticular symptoms with persistent supine position (frog-leg position), concomitant cutaneous nodules, infiltrated and fissured perianal lesion and cervical infiltrated plaques.

During follow-up, 20 years after diagnosis, the patient was found to have been developing multiple nodular tumors and undergoing numerous excisions by Plastic Surgery group, with postsurgical relapsing behavior. She has been followed-up due to dermatological and orthopedical symptoms without systemic involvement so far and with diagnosis of JHF (Figures 5 and 6).

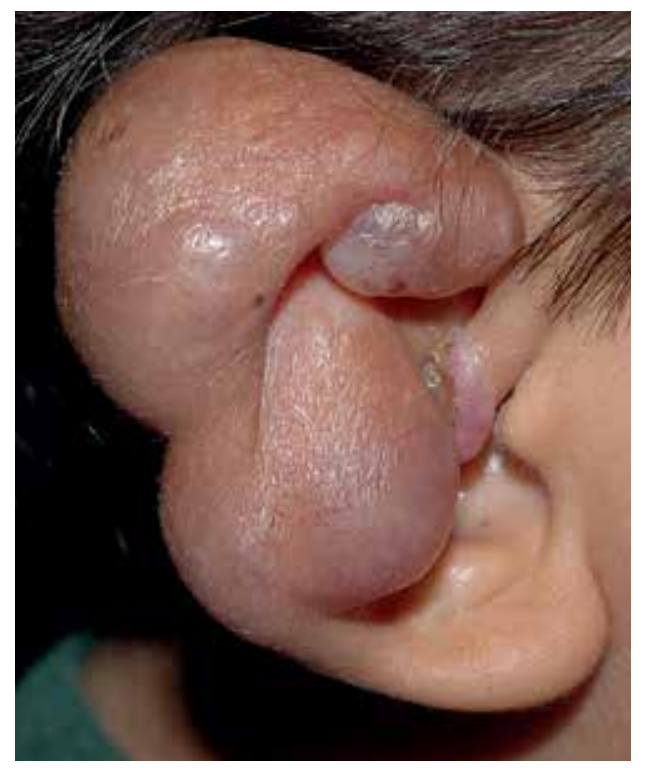

Figure 1:

Case 1: Erythematous-violaceous nodular tumorous lesion affecting the anatomical structure of auricular pavilion

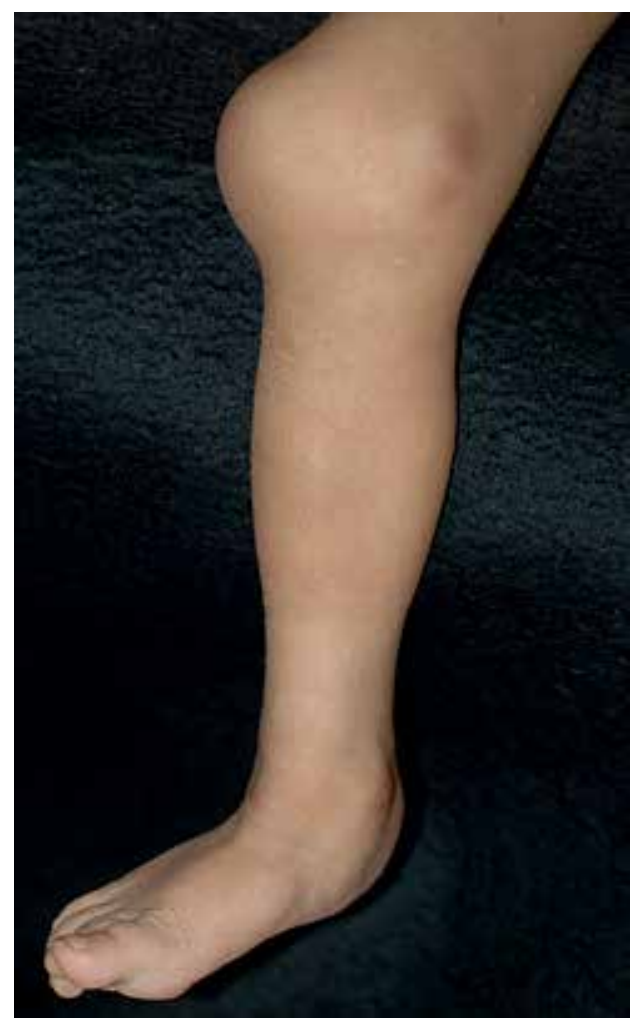

Figure 2:

Case 1: Tumor formation and deformity of knee and nodular tumoral lesions in ankle and lateral side of foot 


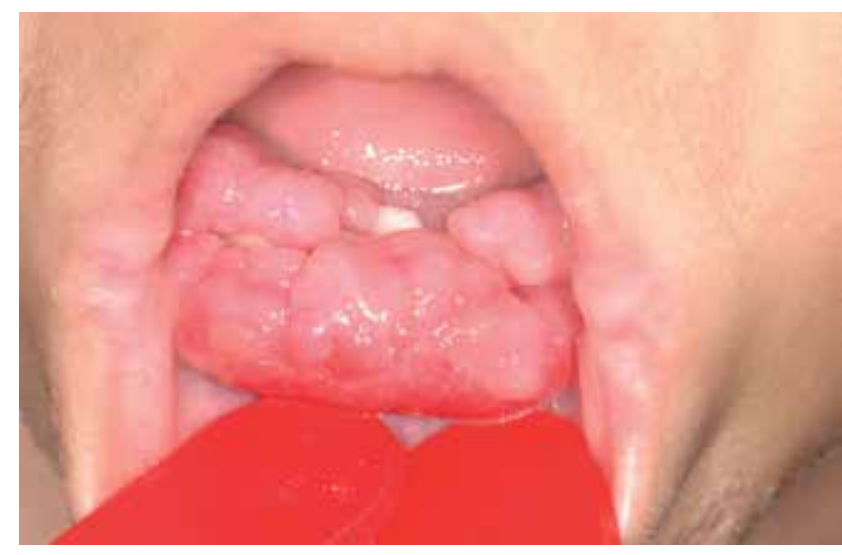

Figure 3: Case 1: Intense gingival hyperplasia burying the teeth in lower jaw

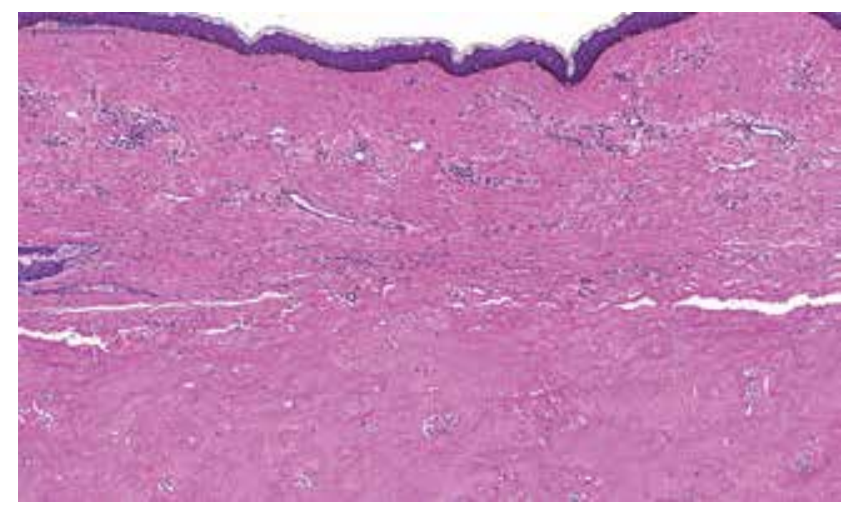

FIgURE 4: Case 1: Atrophic epidermis and dermis showing rare adnexal structures and filled by hyaline, amorphous, eosinophilic and paucicellular material

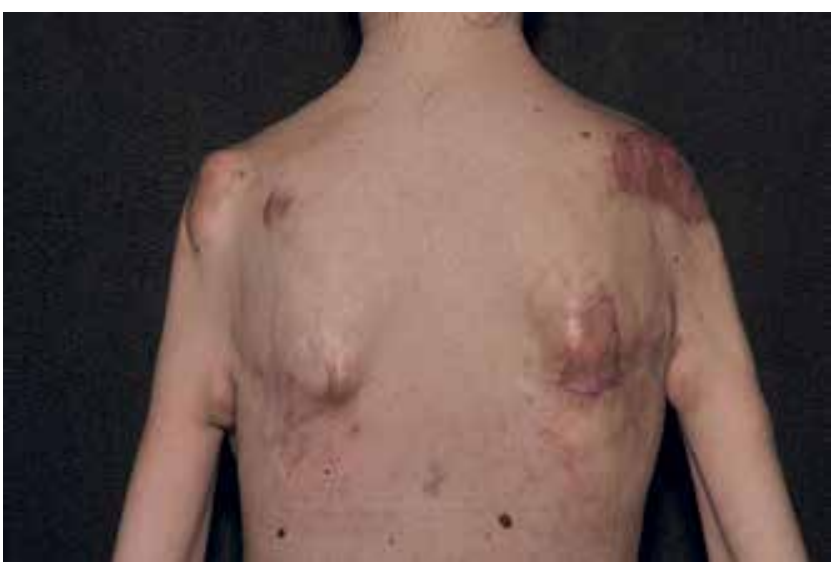

Figure 5: Case 2: Tumors on bone eminences of shoulder, shoulder blade and medial face of the arms. Post-excision surgical scars of specific lesions

\section{DISCUSSION}

The proposal to merge "juvenile hyaline fibromatosis" (OMIM 228600) and "infantile systemic hyalinosis" (OMIM 236490) into a single name, hyaline

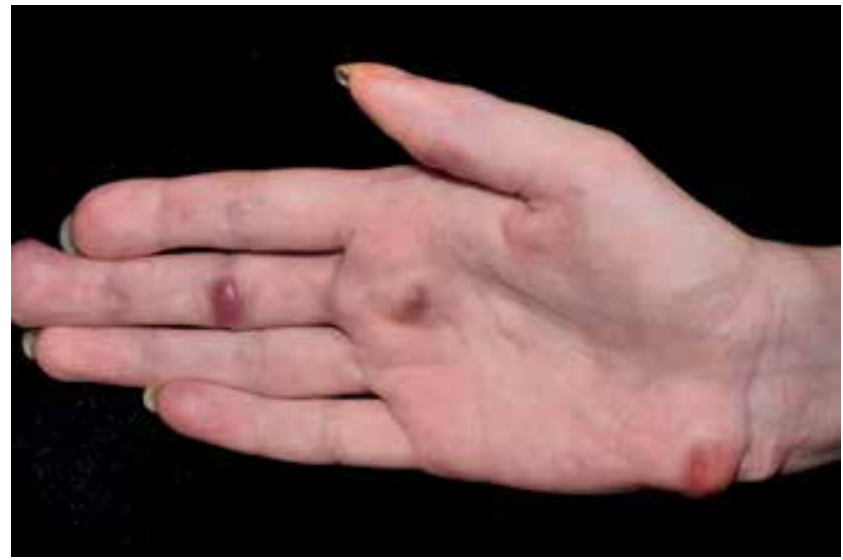

FIGURE 6: Case 2: Erythematous-violaceous tumoral nodular lesions on palm and wrist

fibromatosis syndrome, besides the didactic purpose is based on the identification of molecular defect common to both diseases, expressing genotypic and phenotypic variables consequent to different possible mutations (missense, frameshift, in-frame, nonsense and splicesite) of the same gene (ANTXR2; OMIM 608041). ${ }^{1}$ This gene encodes a transmembrane protein that links itself to laminin and to collagen IV, which suggests alteration in adhesion of the basement membrane to the extracellular matrix and in endothelial cell morphogenesis. It is also supposed that alterations in gene ANTXR2 allow extravasation of hyaline material through the basement membrane to the perivascular space, which would explain histological findings observed in both diseases (JHF and ISH). The histological pattern of cutaneous lesions is proliferation of fibroblasts, soaked in hyaline PAS+ material. Cellularity is variable and inversely proportional to the intensity of hyaline deposit. Staining for amyloid substance is negative.

Accumulation of hyaline material on the dermis is persistent and progressive and lesions evolve from the papule stage to nodules and tumors. ${ }^{9}$ Lesions that were initially pearl-like acquire an erythematous-violaceous or frankly violaceous aspect. Tumorous lesions may ulcerate and become infected. The most common locations are the cephalic segment and over joints.

Therapeutic approach is palliative consisting of excision of cutaneous and mucosal lesions according to technical possibilities and the intensity of aesthetic and functional damage. Physical therapy and nutritional adequacy are mandatory to minimize osteoarticular, muscular and nutritional repercussions. It is important to emphasize that the intellectual capacity is preserved. The authors highlight the importance of early diagnosis, familial genetic counseling and multidisciplinary follow-up. 


\section{REFERENCES}

1. Denadai R, Raposo-Amaral CE, Bertola D, Kim C, Alonso N, Hart T, et al. Identification of 2 novel ANTXR2 mutations in patients with hyaline fibromatosis syndrome and proposal of a modified grading system. Am J Med Genet A. 2012;158A:732-42

2. Fong K, Rama Devi AR, Lai-Cheong JE, Chirla D, Panda SK, Liu L, et al. Infantile systemic hyalinosis associated with a putative splice-site mutation in the ANTXR2 gene. Clin Exp Dermatol. 2012;37:635-8.

3. Nofal A, Sanad M, Assaf M, Nofal E, Nassar A, Almokadem S, et al. Juvenile hyaline fibromatosis and infantile systemic hyalinosis: A unifying term and a proposed grading system. J Am Acad Dermatol. 2009;61:695-700.

4. Denadai R, Bertola DR, Raposo-Amaral CE. Systemic hyalinosis: new terminology, severity grading system, and surgical approach. J Pediatr. 2012;161:173.

5. Muniz ML, Lobo AZ, Machado MC, Valente NY, Kim CA, Lourenço SV, et al. Exuberant juvenile hyaline fibromatosis in two patients. Pediatr Dermatol. 2006;23:458-64

6. Brandão FV, Silva CM, Gontijo B, Guedes AC. Juvenile hyaline fibromatosis and infantile systemic hyalinosis. Case for diagnosis. An Bras Dermatol. 2009;84:677-9.

7. Slimani S, Haddouche A, Haid S, Ladjouze-Rezig A. Juvenile hyaline fibromatosis: focus on radiographic features in adulthood. Rheumatol Int. 2011;31:273-6.

8. El-Maaytah M, Jerjes W, Shah P, Upile T, Murphy C, Ayliffe P. Gingival hyperplasia associated with juvenile hyaline fibromatosis: A case report and review of the literature. J Oral Maxillofac Surg. 2010;68:2604-8

9. Tzellos TG, Dionyssopoulos A, Klagas I, Karakiulakis G, Lazaridis L, Papakonstantinou E. Differential glycosaminoglycan expression and hyaluronan homeostasis in juvenile hyaline fibromatosis. J Am Acad Dermatol. 2009;61:629-38.

10. Tzellos TG, Batzios SP, Dionyssopoulos A, Karakiulakis G, Papakonstantinou E. Differential expression of matrix metalloproteinases and proteoglycans in Juvenile Hyaline Fibromatosis. J Dermatol Sci. 2011;61:94-100.
MAILING ADDRESS:

Silvio Alencar Marques

Departamento de Dermatologia e Radioterapia. Faculdade de Medicina.

18618-970 - Botucatu - SP

Brazil

E-mail: smarques@fmb.unesp.br

How to cite this article: Marques SA, Stolf HO, Polizel JO, Munhoz T, Brandão MC, Marques MEA. Hyaline fibromatosis syndrome: cutaneous aspects. An Bras Dermatol. 2016;91(2):226-9. 